\title{
Supporting motivation in teams working remotely: The role of basic psychological needs.
}

\begin{abstract}
The current disruptive and abrupt transition to remote activities that educational institutions are facing represents a major challenge for the entire academic community. While most concerns have centred on how learning activities may successfully transit from face-to-face to remote delivery, little attention has been given to how educators can be supported in this new unchartered territory. In this article, we discuss the crucial of role team leaders and how their management and leadership style may have great potential to support educators' motivation. Based on Self-determination Theory, we offer a framework through which team leaders may contribute to create optimal remote working environments for educators. We argue that educators' autonomous motivation depends on how they perceive their remote work environment as supportive of their basic psychological needs of autonomy, competence and relatedness. Then, we highlight a series of practical recommendations by which team leaders may be more needs-supportive. Working from home requires space, trust, open communication and flexibility, especially considering that team members may have different clinical or personal circumstances. We therefore hope these suggestions are helpful to cultivate educators' autonomous motivation, which is beneficial not only for themselves but also for others in their institution, including their co-workers and students.
\end{abstract}




\section{Supporting motivation in teams working remotely: The role of basic psychological needs.}

The current disruptive and abrupt transition to remote activities that many educational institutions are facing in response to the COVID-19 pandemic represents a major challenge for the entire academic community. This is no exception for health professions education, where this transition has become especially difficult considering its particular experiential and situational approaches to learning, involving clinical settings that might temporarily be unsuitable for academic activities (Eva 2020a).

While most concerns have centred on how learning activities may successfully transit from face-toface to remote delivery, little attention has been given to how educators can be supported in this new unchartered territory (Eva 2020b). Although remote work may represent a feasible solution to this emergency teaching crisis, it does not come without difficulties and challenges. It therefore becomes essential to support educators' adaptation and psychological wellbeing, and to find ways to maintain their initial level of engagement before motivation to work from home starts to decrease.

In this context, the role of team leaders becomes crucial. We do however need to consider that this might also represent a new way of working for them, where well-intentioned actions might affect and undermine their team's motivation. Previous research has reported team leaders' support as a significant predictor of healthcare educators' optimal motivation to work (Orsini et al. 2020). Therefore, the leadership and managerial style of team leaders may have great potential to support or hinder educators' motivation (Fernet et al. 2012). As such, it becomes crucial to consider how team leaders may support educators' motivation in these times of uncertainty and rapid change.

Self-determination Theory (SDT) could be used to provide a framework through which team leaders may contribute to create optimal remote working environments for educators. SDT understands 
motivation as the reasons why we engage in work activities, differentiating between controlled and autonomous motivation, rather than seeing it as a single quantity measure (Ryan and Deci 2017). Controlled motivation involves engagement due to external reasons such as social or material rewards, or avoidance of external or internal pressure. Autonomous motivation on the other hand involves engagement due to genuine interest or by giving value to work activities (Ten Cate et al. 2011). Research shows that educators' autonomous motivation leads to positive outcomes such as self-efficacy, psychological wellness and a learner-centred teaching style (Van den Berghe et al. 2014, Orsini et al. 2020).

According to SDT, whether working remotely or not, educators' autonomous motivation depends on how they perceive the work environment as supportive of their basic psychological needs of autonomy (feeling that one has choices and concurs with work tasks), competence (feeling a sense of self-efficacy in their role), and relatedness (feeling a sense of connectedness or belonging with important others) (Ten Cate et al. 2011). Previous research has shown that when team leaders are more needs-supportive, educators internalise the value of their work efforts and are more autonomously motivated, thus improving performance and displaying higher wellbeing and work satisfaction (Gagné et al. 2018, Orsini et al. 2020). In light of this, we believe that it is timely and pertinent to raise awareness of how team leaders might support these needs when educators are working in remote environments. The following recommendations come from our own experiences in delivering online programmes and working in remote environments, and from the vast literature on SDT applied to educational and organisational settings (Pelletier and Rocchi 2016, Gagné et al. 2018).

Firstly, team leaders could support autonomy giving choice and voice to their team members to promote a sense of volition. In an attempt to control and assure quality when working remotely, team leaders may tend to be overenthusiastic in achieving accountability through micromanagement or 
surveillance, which may lead to a decrease in engagement and creativity (Ryan and Deci 2017). Conversely, working from home requires space, trust, open communication and flexibility, especially considering that team members may have different clinical or personal circumstances that might require non-traditional working schedules and self-organisation of tasks. It is also important for team leaders to make sure that everyone has a sense of ownership over the tasks they are performing, choosing how things are done and providing input in decision-makings. In summary, it is much more important to empower educators rather than to control their activities to increase motivation and productivity.

Secondly, to support educators' competence and make them feel effective in their work from home, team leaders need to provide clear structure and guidance. Some educators might find themselves doing too much work with an unnecessary overload, whereas amongst others, the lack of structure might lead to underload and low demands on their role. Both work overload and underload have been associated with stress and burnout (Johnstone 1990). Hence, providing structure through establishing and maintaining timeframes and goals, but also setting limits, represents a strong input for educators' feelings of competence and self-efficacy (Pelletier and Rocchi 2016). Team leaders should also be mindful that not all educators have the same skills for remote work, and therefore, balancing their duties, and providing constructive and timely feedback becomes critical. Team leaders should identify areas in which educators are struggling and need support, and/or areas in which they are flourishing and could support others.

Finally, relatedness is the toughest need to address while working remotely, due to physical isolation, the absence of non-verbal support, and feelings of being left out. Unlike working face-to-face, establishing close and stable relationships in remote work can be particularly hard. Team leaders need to pay special attention on how to support meaningful connections and maintaining communication with team members. This can be done both at an individual level through regular contact (e.g., emails, 
phone and video calls), but most importantly, at a group level aiming to develop an online community. The use of weekly video calls, social media and a permanent teamwork collaboration platform can be useful to come together and check in on everyone and also to share knowledge either with regards to technology, education or discipline-specific issues. However, team leaders should balance this, allowing and respecting the team's time for disconnection, considering individual needs.

As we do our best to embrace online remote work in these times of uncertainty, team leaders' management and leadership style should especially consider their team members' basic psychological needs to promote autonomous work motivation and job commitment. Cultivating educators' autonomous motivation is beneficial not only for educators themselves, but also for others in their institution, including their co-workers and students.

\section{References}

Van den Berghe L, Soenens B, Aelterman N, Cardon G, Tallir IB, Haerens L. 2014. Within-person profiles of teachers' motivation to teach: Associations with need satisfaction at work, needsupportive teaching, and burnout. Psychol Sport Exerc. 15(4): 407-417.

Ten Cate O, Kusurkar R, Williams G. 2011. How self-determination theory can assist our understanding of the teaching and learning processes in medical education. AMEE Guide No. 59. Med Teach. 33(12): 961-973.

Eva KW. 2020a. Strange Days. Med Educ. [accessed 2020 April 6]. DOI: 10.1111/medu.14164

Eva KW. 2020b. Medical Education Adaptations: Really Good Stuff for Educational Transition during a Pandemic. Med Educ. [accessed 2020 April 6]. DOI: 10.1111/medu.14172

Fernet C, Guay F, Senécal C, Austin S. 2012. Predicting intraindividual changes in teacher burnout: The role of perceived school environment and motivational factors. Teach Teach Educ. 28: 
514-525.

Gagné M, Deci EL, Ryan, RM. 2018. Self-determination theory applied to work motivation and organizational behavior. In: Ones D, Anderson N, Sinangil H, Viswesvaran C, editors. The SAGE handbook of industrial, work \& organizational psychology: Organizational psychology,

Vol. 2, 2nd ed. Thousand Oaks (CA): Sage Reference, p. 97-121.

Johnstone M. 1990. Stress in Teaching: An Overview of Research. Edinburgh.

Orsini C, Tricio J, Segura C, Tapia D. 2020. Exploring teachers' motivation to teach: A multisite study on the associations with the work climate, students' motivation, and teaching approaches. J Dent Educ. [accessed 2020 April 6]. DOI: 10.1002/jdd.12050

Pelletier LG, Rocchi M. 2016. Teachers' motivation in the classroom. In: Liu WC, Wang JC, Ryan RM, editors. Building autonomous learners. Sngapore: Springer, p. 107-127.

Ryan RM, Deci EL. 2017. Self-determination theory: Basic psychological needs in motivation, development, and wellness. New York: Guilford Publications. 